\title{
O sucesso do inacabado: Clarice Lispector e sua “Children's Corner" na revista Senhor
}

\author{
MARIELA MÉNDEZ \\ University of Richmond
}

\begin{abstract}
In 1959, when the sophisticated magazine Senhor was launched in Rio de Janeiro, the renowned writer Clarice Lispector was invited to join this new publishing venture targeted at educated upper-class men. As a separated woman in need of an income to support herself and her two children, Lispector accepted the offer, regularly contributing with chronicles/stories, and starting at the end of 1961 a column that she named "Children's Corner" in the section "Sr. \& Cía." These contributions are fragmentary, exploratory, somewhat hinting at failure. This article reads Lispestor's texts for Senhor as interventions that enact a rupture in a narrative of growth, progress, and development geared towards a heteroreproductive future. As it unsettles this ideology, Lispector's "Children's Corner" also stages new modes of relationality that defy the ideas of human exceptionalism and human mastery over matter and nature.
\end{abstract}

Keywords: New Materialisms, post-humanism, gender, modernization, progress

O segundo conto de Clarice Lispector a aparecer na revista Senhor, "O crime do professor de matemática," vinha acompanhado no sumário pelo comentário: "Como diriam os ingleses, 'Clarice Lispector Rides Again"” (junho 1959). Desde o começo da icônica revista carioca, o nome da escritora posicionou-se como presença assídua ao lado dos de intelectuais, escritores e artistas como Luiz Lobo, Nelson Rodrigues, Carlos Scliar, Glauco Rodrigues, Bea Feitler, Rubem Braga, Fernando Sabino, João Guimarães Rosa, "um grupo de colaboradores que representava ou veio a representar anos mais tarde a nata da intelectualidade 
brasileira e alguns dos nomes internacionais mais importantes" (Basso 14). Senhor despontou no Rio de Janeiro em março de 1959, no contexto das transformações gráficas e de conteúdo pelas quais atravessava a imprensa brasileira, espelhando a modernização econômica, social e cultural do Brasil sob o impulso desenvolvimentista do governo de Juscelino Kubitschek. O Plano de Metas da presidência de JK (1956-1961) tentava atacar os problemas crônicos do Brasil-energia, transporte, alimentação, indústria de base e educaçãoestimulando o consumo da classe média, a industrialização e a urbanização de um país que almejava fazer parte ativa do cenário mundial. Neste sentido, a construção da nova capital, Brasília, concebida por Oscar Niemeyer e Lúcio Costa e inaugurada em abril de 1960, foi a metáfora perfeita da modernização do país e da capacidade de os brasileiros vivenciarem "cinquenta anos em cinco," o lema da campanha do presidente. A modernização da imprensa refletia o que estava acontecendo no resto da sociedade brasileira, levando a "uma transformação [...] até então inédita no país." Ana Luiza Cerbino enumera exemplos de uma experimentação gráfica sem precedentes no Brasil: "a reforma gráfica do Jornal do Brasil, liderada por Janio de Freitas; a criação da revista Senhor, com direção de arte de Carlos Scliar e Glauco Rodrigues; o design das capas da Editora Civilização Brasileira, criadas por Eugenio Hirsch, e os da Editora da Autor, de Bea Feitler; além das capas do Selo Elenco, projetadas por Cesar Villela" (2). Com uma tiragem de 45.000 exemplares, Senhor tornou-se um dos símbolos da célere modernização da imprensa e logo se transformou num marco na história da imprensa brasileira nessas décadas, tanto pela alta qualidade gráfica, o requinte do design e o selo artístico dos renomados artistas plásticos Scliar e Rodrigues, quanto pela representação, nas suas páginas, das mudanças de costumes e comportamentos ligadas às transformações políticas, sociais e econômicas.

Apesar de a revista expor as transformações de uma sociedade brasileira que tinha acolhido a euforia da modernização, nela persiste, com frequência, a ideologia conservadora na base do projeto político, social e econômico. No seu ensaio "From Working Mothers to Housewives," o historiador Joel Wolfe contrapõe a condição social das mulheres durante o governo de Getúlio Vargas e a situação delas durante o mandato do JK. Embora houvesse a tentativa de capacitar ambos os sexos para a indústria automóvel - a peça central do projeto desenvolvimentista — a divisão do trabalho enraizava-se nos papéis tradicionais 
dos gêneros, uma vez que "men operated huge stamping equipment, women sewed seat cushions" (Wolfe 102). Nas páginas da Senhor, os comportamentos ainda são identificados como "femininos" ou "masculinos" e o ideal continua sendo a relação heterossexual, se bem que sobrem os artigos que encorajam o leitor a ficar solteiro. "O senhor" a quem se dirigia o texto-padrão ficava encarregado de passar valores às novas gerações, representadas nos anúncios por um menino, por assim dizer, um senhor em miniatura (Figura 1). De um lado, a revista parece afirmar a transmissão de valores viável somente através da repetição de uma linearidade hetero-reprodutiva, conforme Jack Halberstam, sinalizada pelo nascimento, o casamento, a reprodução e a morte (In a Queer Time and Place 2). De outro lado, percebe-se que há em Senhor uma certa ambivalência nas representações dos gêneros e das sexualidades que talvez tivesse a ver precisamente com as inumeráveis mudanças nos hábitos e costumes daquele período.

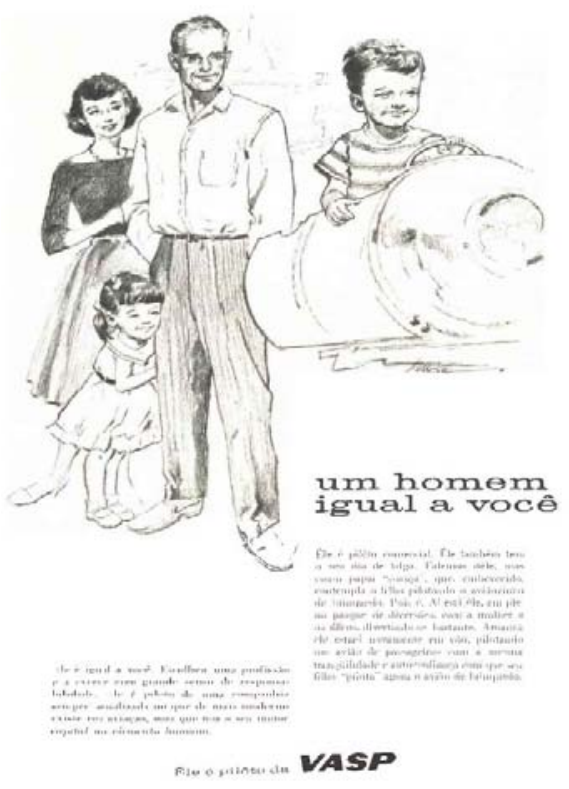

Figura 1: Senhor, agosto 1960

As contribuições de Lispector na prestigiada revista aprofundam a ambiguidade ao instaurar modos de relacionamento que fogem da ideologia 
binária e interrompem a linearidade hetero-reprodutiva. Este artigo examina a "desorientação" das contribuições clariceanas, a desordem que tanto os contos da escritora como a coluna "Children's Corner" composta por ela inauguram, apontando para uma subversão da ideologia de gênero e sexualidade na base do projeto desenvolvimentista e da sociedade de consumo decorrente dele. Ao falar de "desorientação," minha análise inspira-se na interpretação que Sara Ahmed faz da orientação sexual. "Ficar desorientado" é, segundo Ahmed, ficar "off-line" porquanto "to be 'in line' is to direct one's desires toward marriage and reproduction; to direct one's desires toward the reproduction of the family line" (74). O artigo visa explorar como os escritos de Lispector na revista Senhor não ficam em linha com a orientação hetero-normativa do projeto desenvolvimentista.

Se lembrarmos do assim chamado universo feminino tão sutilmente retratado na ficção de Lispector, não é surpreendente que a escritora tenha publicado alguns de seus contos mais famosos numa revista que, apesar de se dirigir explicitamente aos senhores, chega também às leitoras. Na verdade, as esposas $\mathrm{e}$ as namoradas dos senhores liam a revista, conforme a pesquisa da ENOPEmpresa Nacional de Organização e Pesquisa Ltda.—que, depois de receber as respostas das cartas-questionário, afirma o sucesso da revista nesse setor da população: "o que não suspeitávamos, porém, é do seu sucesso entre as senhoras (e senhoritas)" (fevereiro 1960). No entanto, pretendemos apontar neste artigo que as contribuições clariceanas vão além da divisão rígida entre o feminino e o masculino. Antes de analisarmos a perturbação dessa divisão rígida no interior da revista e, em especial, no interior da escrita clariceana, vamos esclarecer como a escritora veio a fazer parte da empreitada jornalística de Nahum Sirotsky.

Ainda no exterior, onde morava com o seu marido diplomata, Lispector ficava frustrada porque Simeão Leal não tinha mantido a promessa de publicar os seus contos e recusava-se a devolvê-los. Clarice decidiu retirar os contos das mãos do Simeão e enviá-los para Nahum Sirotsky e Paulo Francis, que tinham convidado a escritora a publicar na sua nova revista. "A menor mulher do

\footnotetext{
${ }^{1}$ Sirotsky já tinha uma trajetória na imprensa brasileira, tendo passado pela redação dos jornais $O$ Globo e Diário da Noite e dirigido as revistas Visão e Manchete. Sirotsky convidou Carlos Scliar, e os dois elaboraram a boneca de publicação. Simão Waisman, uns dos sócios da Editora Delta responsável pela edição da revista, Abrahão Kogan, o sócio mais velho e tio de Waisman, Sergio, irmão de Abrahão, e Lorch, genro de Abrahão, todos gostaram da boneca e deram carta branca para
} 
mundo" apareceu no primeiro número, inaugurando uma colaboração que iria durar até o final da publicação. Paulo Francis sublinha que, junto com Nahum Sirotsky, Carlos Scliar e Luiz Lobo, eles concordaram em "aconchegar" a Clarice, já que os editores fugiam do caráter "moderno" da sua literatura. ${ }^{2}$ "Parece brincadeira lembrar que Clarice Lispector," diz Francis, "antes de SENHOR era conhecida apenas por uma coterie de intelectuais" (Basso 32). A Senhor orgulhava-se de ter ocasionado um redescobrimento da escritora no Brasil: "um jornal do Rio, em editorial, mencionou que os contos de Clarice Lispector em SENHOR eram o acontecimento literário de 1959 . . SENHOR teve foi o prazer de dar-lhe destaque e divulgação que lhe faltavam no meio editorial brasileiro. A renovação de interesse de diversas editoras pela obra de Clarice se deve, em parte, ao sucesso que seus contos obtiveram aqui" ("Alguns senhores e uma senhora," março 1960, 7). Eram os contos que iriam fazer parte da renomada coleção Laços de família, finalmente publicada em 1960 pela editora Francisco Alves. Em junho de 1959, Lispector voltou ao Brasil depois de dezesseis anos; acabava de se separar e precisava duma renda que lhe permitisse manter os seus dois filhos. $\mathrm{O}$ fracasso em publicar esses contos durante os quatro anos que ficaram nas mãos de Simeão Leal, tornou-se sucesso: Lispector pôde publicar os seus contos, assim como o romance A maçã no escuro, em 1961, e se estabeleceu no bairro do Leme, no Rio de Janeiro, com os seus dois filhos, Pedro e Paulo.

Lispector já pensava na "Children's Corner" anos antes de unir-se à Senhor. A menção dessa seção por parte da escritora fez a primeira aparição em O Jornal em 1946 e, mais tarde, várias vezes no Diário Carioca, que mostrava certa fixação pela imagem de Clarice. ${ }^{3} \mathrm{Na}$ edição de janeiro de 1962 da revista Senhor, na coluna "Bastidores," há uma lista de colaboradores que faz referência à coluna de Lispector: "Clarice é também a CL, uma das atrações permanentes de 'Sr. \&

Sirotsky fazer a revista. O quadro de editores era composto por Scliar, Francis, Glauco Rodrigues, e Luiz Lobo, junto com o cartunista Jaguar.

${ }^{2}$ Ver Gottlib (383). Quase a metade dos contos de Laços de família apareceram na revista Senhor: "Uma galinha," “A imitação da rosa," "Feliz aniversário," “A menor mulher do mundo," "O crime do professor de matemática" e "O búfalo."

${ }^{3}$ Agradeço a Flávia Vieira da Silva do Amparo por esses dados. Amparo afirma que, dentre as publicações presentes no acervo da Hemeroteca da Biblioteca Nacional em Rio de Janeiro, é precisamente no Diário Carioca em que aparecem mais citações sobre a Clarice. Além disso, ela acrescenta que a atividade de Lispector nos jornais é, na verdade, um laborátorio para a sua escrita, opinião com que concorda Vilma Arêas. 
Cia." (janeiro 1962, 8). A criação de Clarice no final de 1961 começou fazendo parte da seção "Sr. \& Cia." que abria a revista apresentando notas bem curtinhas sobre livros, filmes, teatro, celebridades e, ainda, "muitas vezes material que não poderia ser aproveitado nas demais páginas da revista" (Basso 18-9). Com o passar do tempo "Children's Corner" transformou-se numa seção com vida própria, separada da "Sr. \& Cia."

A coluna criada por Lispector revela-se duplamente enigmática. Antes de mais, a escolha do nome não deixa de ser curiosa. A utilização do inglês é num certo sentido o resultado de um momento em que a imprensa brasileira se modernizava seguindo padrões norteamericanos, mas, ao mesmo tempo, nos faz pensar na ideia de status. Segundo o testemunho de Sirotsky, Simão Waisman "queria uma publicação compatível com o programa da editora e que pudesse ser como um cartão de visitas" (Basso 12), dado que a Editora Delta iria editar a enciclopédia Delta-Larousse a partir de 1962. O fato de Senhor se transformar em símbolo de status - e em cartão de visitas para a Editora Delta — traduzia-se no preço. ${ }^{4}$ Sirotsky lembra-se da ideia que ele apresentou originalmente a Simão Waisman e afirma: "Teria o tamanho de Esquire e preço de capa várias vezes mais caro do que a mais cara do Brasil para que fosse símbolo de status" (Basso 12). A última edição, em janeiro de 1964 , ainda apresentava um anúncio com uma imagem da revista na estante ao lado de objetos de arte e a legenda: "Fica bem em sua estante a presença da revista SENHOR ... SENHOR é uma revista para ler e colecionar. Assegure a presença regular da SENHOR em sua casa fazendo hoje mesmo uma assinatura anual." 5 Ancorada em quatro eixos

\footnotetext{
${ }^{4}$ Anna Figueiredo destaca que "a utilização do critério de status" para diferenciar os indivíduos "no lugar do critério de "classe"” estendeu-se drasticamente no período 1954-1964, junto com "a valorização do lazer em detrimento do trabalho, a exaltação da juventude, a 'coação' à felicidade, o hedonismo, a enfatização da personalidade," entre outras (114).

${ }^{5}$ Na primeira troca de proprietários, em agosto de 1961, a Artes Gráficas Gomes de Souza S.A. do grupo Gilberto Huber tornou-se o novo dono da publicação. A AGGS já fazia a impressão e, conforme Lucy Niemeyer, acreditava que "ser proprietário da revista conferia ao grupo empresarial um tipo de prestígio que não seria alcançado através da produção de suas outras publicações, como listas telefônicas" (71). Nessa segunda fase, sob a direção do poeta e jornalista Odylo Costa, filho, a equipe de Nahum Sirotsky permaneceu-Francis e Newton Rodrigues como editores, Michel Burton e Renato de Viana na direção de arte, Jaguar, Glauco Rodrigues e Luiz Lobo como colaboradores - mas somaram-se novos nomes às colaborações. Sob a direção do Reynaldo Jardim, em março de 1962, a revista tornou-se propriedade de Jardim e do publicitário Edeson Coelho, pois Gilberto Huber não estava mais interessado nela. A empresa "Turismo Rio," na qual Coelho estava trabalhando, iria ajudar a financiar a revista, segundo Jardim, "por meio de patrocínios e compra de exemplares" e iria distribuí-la como peça promocional, já que estava construindo um hotel de
} 
temáticos-cultura, política, economia e entretenimento-a revista, mesmo quando mudava suas características ao entrar numa etapa diferente sob a direção editorial do poeta e jornalista Reynaldo Jardim, não deixava de se valer da ideia de prestígio e status para ganhar novas assinaturas. Ao aliar arte e design, Scliar e Rodrigues contribuíram para a concepção de uma publicação sofisticada que tinha como público-alvo o homem e a mulher de alto poder aquisitivo e com bons gostos fornecidos pela sua educação.

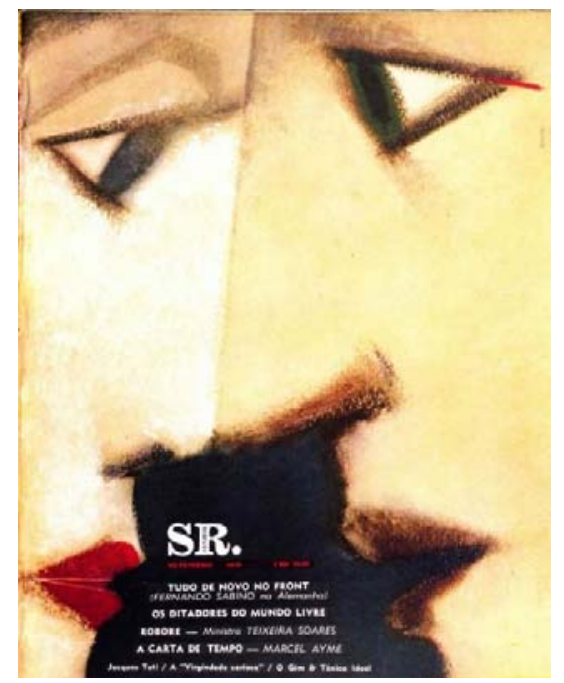

Figura 2: Senhor, setembro 1959

No entanto, os meninos na coluna de Lispector são mais enigmáticos do que o nome propriamente dito. ${ }^{6}$ No interior da revista, a mensagem ficava clara: para o sucesso do programa desenvolvimentista precisava-se reproduzir o modelo hetero-reprodutivo. $\mathrm{O}$ casal heterossexual, esse casal cujas bocas prestes a beijarse ocupam a capa inteira da edição do mês de setembro de 1959 (Figura 2), apresenta-se amiúde nos anúncios da revista. Nesses anúncios é o menino, o senhor em miniatura, quem vai assegurar a continuidade do modelo. Trata-se do

luxo no Rio de Janeiro. Pela falta de aporte financeiro, aos poucos deu-se um esvaziamento do quadro de funcionários (Basso 64).

${ }^{6}$ É bom lembrar, como afirma Amparo, que Clarice utilizou o nome "Children's Corner" para nomear diferentes textos ao longo da sua carreira. A escolha do nome, baseado na composição homónima de Claude Debussy (1908), é testemunho da presença forte da música na vida de Clarice. Conforme afirma Amparo, a música exerceu grande influência em sua literatura. 
menino com letras maiúsculas - "the Child"-que, segundo Lee Edelman, "has come to embody for us the telos of the social order and come to be seen as the one for whom that order is held in perpetual trust," o menino na base do que Edelman chama de futurismo reprodutivo (No Future 11). Os meninos da coluna de Lispector destoam daqueles nos anúncios que nos fazem pensar no Child do teórico Edelman.

Longe de ficarem encarregados da preservação do modelo heteroreprodutivo, tanto os meninos quanto os adultos na coluna "Children's Corner," assim como aqueles nos contos da escritora publicados na revista, são figuras que agem inesperadamente e ainda de uma forma inapropriada, como veremos mais adiante. Poder-se-ia dizer que os adultos da coluna de Lispector não têm crescido ou "evoluído." Por outra parte, quanto a forma dos textos que constituem a coluna, eles são fragmentários, híbridos, quase inacabados, e esquivam-se da categorização geral dos gêneros literários. Como se a lógica por trás deles fosse a do fracasso, são matérias escritas com "a ponta dos dedos," conforme afirma Vilma Arêas, precipitados, impacientes, escritos sob pressão, "ao mesmo tempo vanguardista[s] e regressivos[s]" (15). Assim como os outros textos que Lispector escreveu ao regressar ao Brasil quando precisava duma renda, os textos de "Children's Corner," essa "produção obrigatória" que obedecia "a sugestões e/ou imposições editoriais," possui uma relação profunda com o restante da sua obra, segundo Arêas (113-15). ${ }^{7}$ No caso da revista Senhor, os fragmentos da "Children's Corner" também guardam relação com o restante da publicação, mas de um jeito diferente. A coluna criada pela escritora e assinada com as iniciais C.L. insere uma narrativa alternativa com respeito àquela que sobressai na revista, a saber, a da ideologia hetero-normativa.

Desde o início, a coluna de Lispector veiculava representações que perturbavam a idealização do papel da mulher como progenitora. A primeira edição de "Children's Corner" em outubro de 1961 começa com o texto "Instantâneo de uma senhora," onde a senhora do título é moradora de uma pensão na Rua São Clemente. Essa senhora "voluminosa, [que] cheirava a quando a galinha vem meio crua para a mesa," "com cinco dentes e a boca sêca,"

\footnotetext{
${ }^{7}$ Arêas esclarece: "julgo não haver dúvidas de que as estratégias textuais utilizadas pela escritora em toda a sua obra são basicamente as mesmas: textos fragmentados, mesmo quando escritos a fio, muitas vezes revelando um surpreendente inacabamento ou indiferença a composições rematadas" (114).
} 
na segunda-feira, "em vez de sair do cuarto, veio da rua" e "disse que passara o domingo na casa do filho, onde pernoitara." A mudança na aparência da senhora após essa visita é notável, para os leitorxs e para os pensionistas: "Estava lisa e com o pescoço claro, sem nenhum cheiro de galinha." Imediatamente, relembramos a mãe do anúncio de Nestlé duas páginas atrás. Os produtos Nestlé celebram os seus quarenta anos a serviço da família brasileira (1921-1961) homenageando à mãe brasileira, aos pediatras, aos distribuidores, aos [nossos] fornecedores e aos [nossos] funcionários. Com isso em mente, eles incluem "a reprodução do bronze comemorativo do $40^{\circ}$ aniversário," "a mais elevada, especial e carinhosa homenagem à Mãe Brasileira.” A imagem da mãe no bronze confirma a descrição: ela é jovem e graciosa e fica atenta à criança em seus braços. Entretanto, no texto de Lispector, a "majestade" da senhora da pensão vem de "o grande volume sustentando por pés minúsculos, [n]a potência dos cinco dentes, [n]os cabelos ralos que esvoaçavam à menor brisa." Além da disparidade entre as imagens, a relação entre a senhora e o seu filho contraria a idealização do anúncio. A mudança positiva que surpreendeu os pensionistas chegou ao fim quando, ao relembrar a casa do filho, "seus olhos se fecharam de náusea. Recolheu-se, vomitou, recusou ajuda quando lhe bateram à porta do quarto." A felicidade do anúncio da Nestlé, presente na reprodução do bronze e nas imagens da mãe feliz alimentando o bebê e conversando com o doutor na parte inferior da página, para a senhora do texto de Lispector é fugaz, efêmera. A idealização que ajuda a consolidar estereótipos em torno da ideia de feminilidade e dos papéis de gênero é posta em questão no caso de "Instantâneo de uma senhora."

Os anúncios na revista Senhor, "colocados no início ou no fim da publicação [...] para que não interferisse[m] no ritmo da leitura" conforme Sirotsky, dirigiam-se claramente ao senhor experiente, sofisticado e vaidoso que precisava demonstrar solidez, segurança e poder (Basso 26). Esse senhor era, segundo a coluna "Bastidores" da edição de julho de 1961: "um homem de 30 a 50 anos, com automóvel, casa, bons quadros e livros bem lidos na biblioteca, exigente no vestir, cuidadoso na seleção das bebidas, de paladar apurado, casado com mulher preocupada com as coisas da cultura" (8). Os senhores da elite que moravam nos grandes centros urbanos liam a revista que lhes ensinava a ser sofisticados, bemsucedidos, a vestir-se bem e a cultivar comportamentos em sintonia com a modernização e o progresso do país. O senhor leitor da revista aparecia assim 
ligado ao consumo tanto dos produtos que começaram a ser acessíveis com o governo do JK, quanto dos bens produzidos por uma indústria cultural que se consolidava nesse período. "Nesse sentido," conforme Basso, "há faustos anúncios de bancos, da indústria automobilística, das companhias aéreas, de produtos masculinos como o charuto e o terno, tudo no estilo da primeira linha" (43). Junto com esses anúncios, a revista inclui outros direcionados àquilo de que o senhor precisa para equipar o seu apartamento de solteiro: móveis, sanitários e, até mesmo, adornos.

Contudo, caso os leitores puserem em dúvida a hegemonia da ideologia hetero-reprodutiva, a edição de janeiro de 1960 é lançada com um encarte de umas dez páginas, o Suplemento Promocional para SR., sob o patrocínio da loja Serva Ribeiro, que promete ao leitor: "Apostamos que você se divertirá à grande, e descobrirá, de amena forma, o roteiro seguro para as compras de aparelhos elétricos ou utilidades para seu lar!" (janeiro 1960, 75). Os atores Irina Grecco e Jardel Filho posam na primeira página como o casal que começa uma viagem pelo interior da loja, "no tranquilo Mar das Boas Compras," e inicia a vida a dois, e nós acompanhamos "a nau do noivado" soltando a imaginação, como exorta o anúncio. Cena após cena, como se fosse um filme, ${ }^{8}$ o suplemento "ABC de utilidades domésticas" mostra o casal brincando com aparelhos domésticos de marcas cujos nomes começam com as diferentes letras do abecedário: A pela Arno, B pela Brastemp e pela Bendix, C pela Cosmopolita e assim por diante até a história do casal acabar e "o casalzinho parte, feliz, como nas histórias românticas, a caminho da Serra do Matrimônio" (98). No suplemento, a W era a letra mágica da fada Walita que, com sua varinha de fantasia, fazia aparecer "a família Walita," composta por todos esses artefatos necessários para o sucesso da família heterossexual. Anna Figueiredo chama a atenção para uma série de anúncios onde o consumo de um objeto sugeria a necessidade de consumir outros tantos objetos e salienta o exemplo da "Família Walita," que nos anúncios parecia aconselhar: "para que uma família esteja completa, para que reine nela a

\footnotetext{
${ }^{8}$ É bom lembrar nesse sentido as palavras de Sirotsky quando afirma que "a direção de arte davase ao luxo de exigir das agências de publicidade um padrão estético para os anúncios, recusando peças que não estavam de acordo com os parâmetros da publicação" (Basso 26). No seu artigo "Sem botar banca, Clarice escreve e aguenta o Brasil," Aparecida Maria Nunes também salienta o rigor estético da revista e cita Carlos Scliar, o diretor de arte que notavelmente criava a revista inspirado no cinema, uma vez que "ele colocava nas paredes as páginas que ia compondo, uma ao lado da outra, para criar cada revista como se fosse um filme" (Nunes 64).
} 
felicidade, é preciso que não falte nenhum de seus membros e que eles estejam sempre juntos uns dos outros" (111). Além do mais, era preciso consumir todos os produtos Walita porque tratava-se de uma empresa que se orgulhava nos seus anúncios do seu investimento constante na elevação do padrão de vida de seus funcionários.

Embora Figueiredo não aborde a questão de gênero ao analisar os padrões de consumo em relação ao comportamento político no Brasil entre 1954 e 1964, salienta numa nota de rodapé: "Chama a atenção a quantidade de artigos escritos por publicitários e de anúncios que identificam a mulher como a grande consumidora, o público preferencial de toda a publicidade nos anos 60" (114). Segundo Luiz Lobo, o editorial do primeiro número dirigido às senhoras foi uma brincadeira (Basso 17); no entanto, os editores com certeza tinham conhecimento do fato de as senhoras serem as que mais compravam revistas:

Minhas Senhoras

Como por muito tempo desejei fazer uma revista e sempre ouvi dizer que as mulheres é que compram ou condenam uma revista à morte, dirijo-me a vocês (se me permitem o tratamento). Em primeiro lugar para pedir desculpas. Em segundo lugar para pedir compreensão. Em terceiro lugar para explicar-me. E em último lugar para dar-lhes uma garantia. (março 1959, 10)

Para além do tom da revista - "mistura entre sério e zombeteiro" ("Bastidores," dezembro 1960, 8)—nesse primeiro editorial percebe-se a experiência profissional duma equipe de redação ciente da segmentação do mercado das revistas em termos de gostos, hábitos, passatempos, esportes, etc. Concretamente, havia publicações focadas no universo feminino, como Cláudia, Capricho, Querida e outras dirigidas ao público masculino, como Quatro Rodas. ${ }^{9}$ Senhor destacava-se por ser uma revista com capacidade de atrair tanto leitores homens como mulheres.

\footnotetext{
${ }^{9}$ A segmentação do mercado de revistas foi concomitante com o aumento de consumo e com o fato das revistas se transformarem em veículos de publicidade e propaganda, em "revistas vitrine," segundo apontam Baptista e Abreu: "Em face disso, surgem veículos especialmente voltados para atender às necessidades de clientes específicos" (19). Assim, a revista Cláudia (1961) centrou-se
} 
O consumo de produtos específicos não só se apresentava na Senhor como funcional para a ideologia hetero-reprodutiva mas também frisava a ideia de progresso e evolução que definia o programa desenvolvimentista. Até mesmo o nome da revista faz alusão à ideia de maturidade e experiência, e dessa maneira o texto-padrão identificava o seu tipo de leitor. Para modernizar-se, o Brasil precisava evoluir e amadurecer e daí a abundância de imagens de progresso e prosperidade que invadiram as revistas desse período. Figueiredo esclarece: "até o final dos anos 50 o tema da modernidade vinha, na grande maioria das vezes, associado à ideia de progresso, cuja realização pressupunha a constante sucessão de etapas, sendo cada nova etapa resultado de uma evolução da anterior" (31). Tratava-se de uma evolução simbolizada, por exemplo, pelos caminhões Ford, que conduziam o progresso de norte a sul do país, e a Eletrobrás, que iria trazer aos campos a energia elétrica necessária para o desenvolvimento (Figueiredo 33). No que diz respeito aos anúncios e a algumas matérias, Senhor não fugia do padrão examinado por Figueiredo nas revistas $O$ Cruzeiro e Manchete. Na edição de novembro de 1960, a revista colocava em suas páginas um anúncio da FNMFábrica Nacional de Motores — com a legenda "O Caminhão FNM ajuda o Brasil a crescer."

Se pensarmos nos textos quase inacabados da coluna de Clarice como um laboratório para a sua escrita, conforme afirma Flávia Amparo ("Clárice Lispector: From Poetic Corners”), é possível argumentar que são textos prematuros, que ainda não têm evoluído. De fato, vários desses textos iriam fazer parte da segunda parte do volume A legião estrangeira publicado em 1964, sob o título "Fundo de gaveta," e seriam também publicados separadamente com o título Para não esquecer em 1978, sete anos após a morte da escritora. Abandonados no fundo da gaveta, são textos que ironicamente poderiam ser esquecidos, já que nos incitam à tentação de descartá-los, ${ }^{10}$ se não fosse pelas

na moda feminina, por exemplo, e as revistas Placar (1970) e Quatro Rodas (1960) direcionaram a atenção para o esporte e os carros, respectivamente. Além disso, conforme Baptista e Abreu: "a percepção mercadológica aplicada ao mercado editorial" "subdivide os grupos" e "faz surgir revistas especializadas como Casa Cláudia, antigua seção da revista Cláudia, da Editora Abril, Arquitetura e Construção, também originária da mesma seção de Cláudia, mas com o propósito de apresentar soluções gráficas e projetos de edificações" (19-20).

${ }^{10}$ Num sentido, A legião estrangeira fracassou, já que, como revela Lispector: "o livro foi inteiramente abafado pelo A paixão segundo G.H., que saiu na mesma ocasião" (Outros escritos 148). 
palavras de Lispector que se apresentam como prefácio da segunda parte de $A$ legião estrangeira:

Por que tirar do fundo da gaveta, por exemplo, "a pecadora queimada," escrita apenas por diversão enquanto eu esperava o nascimento de meu primeiro filho? Por que publicar o que não presta? Porque o que presta também não presta. Além do mais, o que obviamente não presta sempre me interessou muito. Gosto de um modo carinhoso do inacabado, do malfeito, daquilo que desajeitadamente tenta um pequeno vôo e cai sem graça no chão. (127)

A predileção da escritora pelo desajeitado, pelo desastrado e defeituoso tem a ver ademais com o seu processo de escrever, "feito de erros-a maioria essenciais," segundo a descrição no texto "Submissão ao processo" na primeira edição da “Children's Corner" (outubro 1961, 6). Nesse texto, a escritora afirma que escrever é um processo feito de "vegetativa atenção, de sentimento constante (não pensamento) que não conduz a nada, não conduz a nada" e insere entre parênteses as palavras do seu filho — como é hábito na sua coluna: "(Mamãe, me disse o menino, o mar está lindo, verde e com azul, e com ondas! está todo anaturezado! todo sem ninguém ter feito ele!)." Faz-se necessário ter a "pesada paciência vegetativa"- " "ficar de pé junto da planta para vê-la crescer e não se vê nada" - da que fala a escritora nesse texto enigmático para representar o mundo sem adulterá-lo e sem acreditar que nos o temos criado (outubro 1961, 6).

A "vegetativa atenção" leva ao sucesso na representação do mundo exterior intacto, mesmo que Clarice fale de fracasso, da "tentativa fracassada de atingir o que existe" (40) ao responder à pergunta "O que acha da sua própria obra?" em "Encontro com 5 escritores" na edição de julho de 1961. Através de suas personagens, Lispector retrata modos de relacionamento entre humanos e não humanos nos quais tenta se fazer todo o possível para não mudar a natureza do outro, aceitando assim a sua essência, a sua natureza inalterável, e, em última instância, a sua agência. $O$ verdadeiro crime do professor de matemática não é ter enterrado um cão desconhecido em lugar do cão que ele tinha abandonado, mas sim não ter aceitado a natureza irredutível de ambos, o homem e o cão: 
Porque, embora meu, nunca me cedeste nem um pouco de teu passado e de tua natureza. E, inquieto, eu começava a compreender que não exigias de mim que eu cedesse nada da minha para te amar, e isso começava a me importunar. . . Minha ferocidade e a tua não deveriam se trocar por doçura: era isso o que pouco a pouco me ensinavas, e era isto também que estava se tornando pesado. Não me pedindo nada, me pedias demais. ("O crime do professor de matemática” 78)

Incapaz de tolerar a agência do cão, o professor não só achava impossível a tarefa de deixar o cão ser um cão sem adulterá-lo, mas também não podia abraçar a possibilidade de um intercâmbio autêntico, de uma interação genuína entre eles. Assim, decidiu abandoná-lo.

Para a narradora convidada ao almoço de obrigação em "A repartição dos pães," o humano nem domina nem possui aquilo com que ele se defronta. "Os tomates eram redondos para ninguém: para o ar, para o redondo ar" em consonância com a dona de casa que "dava o melhor não importava a quem." Nesse almoço quase religioso, tudo ficava "limpo do retorcido desejo humano. Tudo como é, não como quiséramos. Só existindo, e todo. Assim como existe um campo. Assim como as montanhas" (junho 1962, 4). Nessas interações, a dinâmica entre humanos e não humanos poderia entender-se como uma "intraação" na qual ambos constituem-se como entidades. Para a teórica norteamericana Karen Barad, ao contrário da interação—na qual as entidades existem independentemente umas das outras - por intra-ação compreende-se que as entidades se materializam ao se relacionarem. Conforme Barad, "it is through specific agential intra-actions that the boundaries and properties of the 'components' of phenomena become determinate" (133). Em vez do pensamento antropocêntrico, o relato neomaterialista de Barad localiza a agência na própria intra-ação. A agência, para a teórica, não é propriedade exclusiva do ser humano e não é também um atributo, mas "an enactment, not something that someone or something has" (135). Barad ecoa o pensamento do filósofo da ciência Andrew Pickering: "The world makes us in one and the same process in which we make the world" (26). O guarda-roupa "corcunda," "tímido" e "enorme, triste, intruso e bondoso" do "Esboço de um guarda-roupa," na edição de fevereiro de 1962 (8), tem tanta "influência no mundo" como "a bandeira," "a pera," "a árvore," "a 
piscina" da coluna de janeiro de 1963 ("Crítica leve" 78). Nessa coluna cheia das vozes de seus filhos, a natureza apresenta-se "tranqui-la, sem nenhuma piedade" para nós a olharmos sem prejuízo.

As intra-ações entre "actants"—os que possuem agência, conforme a terminologia de Barad-mobilizam emaranhados- “entanglements"-entre humanos e não humanos num espaço-tempo que desafia toda linearidade e toda relação transparente de causa e efeito. Fora de uma lógica de progresso e evolução, elas desestabilizam ao mesmo tempo os mecanismos que regem a sociedade de consumo consolidada sob o programa desenvolvimentista. O que importa nessa sociedade é precisamente a utilidade das coisas, o seu potencial para ser consumidas, como no anúncio da loja Serva-Ribeiro de que já falamos. Daí que as coisas só adquirem valor na medida em que atingem as necessidades dos consumidores até as vezes os bens de consumo e os humanos confundirem uns com os outros. Segundo Figueiredo: "À medida que se humanizavam enceradeiras, fogões e automóveis, tornava-se cada vez mais tênue a linha divisória que separava os homens das mercadorias que lhes eram destinadas e, desse modo, eles se amalgamavam" (99). A "metáfora orgânica tão presente no imaginário desenvolvimentista brasileiro" (Figueiredo 47) também aparecia na revista criada por Nahum Sirotsky, onde a camioneta DKW-VMAG, por exemplo, "é a companheira sempre presente nos momentos alegres," "distinta," "elegante" (maio 1960). A coluna de Lispector, contudo, revela uma mudança da lógica de utilidade para o realismo agencial de Barad e inviabiliza a fusão entre humanos e não humanos. Como sugere Patricia Vieira no seu artigo sobre $A$ paixão segundo G.H. e alguns dos contos de Laços de família, na verdade, muitos deles publicados na revista Senhor: "The face-to-face encounters with plants and animals . . . preclude a metamorphosis of the self into the other" (74). Os encontros com o mundo não humano tanto na coluna "Children's Corner" quanto nos contos publicados fora dela deslocam a centralidade do humano gerando outros modelos de interconexão e intercâmbio.

É curioso que a mesma edição onde é publicada a crônica "Tentação," que logo faria parte de A legião estrangeira - com e sem a segunda parte "Fundo de gaveta"-inclui "Um amor difícil" na coluna "Children's Corner," como se a crônica de Clarice publicada fora da coluna fosse uma resposta ao dilema introduzido dentro dela. Em "Tentação," na página 70 do número de janeiro de 1962, a comunicação entre a menina ruiva com soluço sentada nos degraus de 
sua casa e o basset lindo e miserável, e também ruivo, foge duma economia afetiva de causalidade e lucro que objetiva render resultados. A menina "que viera ao mundo para ter aquele cachorro," "sua outra metade neste mundo," sabia desde o início que não o teria e, assim, eles "se fitavam profundos, entregues, ausentes de Grajaú," porque "ambos eram comprometidos. Ela com sua infância impossível ... Ele com sua natureza aprisionada." Se pelo menos o homem que espanta a narradora e Ivan Lessa em "Um amor difícil" pudesse entender esse tipo de intra-ação. Longe disso, "era por coragem que andava em público com o seu bicho," que não era cachorro como os observadores tinham pensado, mas quati. Assim, a atrapalhação da narradora vinha "de que aquele bicho já não sabia mais quem ele era, e não podia portanto lhe [me] transmitir uma imagem nítida" (4). O monólogo interior da narradora é revelador nesse sentido: "por que é que você faz isso? que carência é essa que faz você inventar um cachorro? e por que não um cachorro mesmo, então? pois se os cachorros existem! Ou você não teve outro modo de possuir a graça desse bicho senão com uma coleira? mas você esmaga uma rosa se apertá-la com força!” (4). Com a sua essência esmagada pelo dono que só deseja possuí-lo, "não perdê-lo para sempre," o quati que se pensava cachorro faz com que a narradora reflita sobre o ódio que ele ia sentir quando descobrisse a sua verdadeira identidade: "o ódio pelo que de pior um ser pode fazer a outro ser-adulterar-lhe a essência a fim de usá-lo" (4), um ódio que lhe daria, segundo a narradora, o direito de massacrar o homem.

Nesses anos da Guerra Fria entre os Estados Unidos e a União Soviética, a conquista do espaço dominava as páginas das revistas, e a revista Senhor não foi exceção. Com "a mistura de sério e zombeteiro" que caracterizava a publicação, o diretor referencia o conflito: "É trágico que estejamos sempre sob o perigo de explodir pelos ares; mas é engraçado, também, que estejamos sob este perigo graças ao nosso domínio do mundo material" ("Bastidores," dezembro 1960, 8). Os modos de relacionamento insinuados na coluna de Clarice questionam o domínio humano sobre a matéria; portanto tornam possível a ação daquilo que fica além do humano. Sob o signo desenvolvimentista, a nova capital Brasília apresenta-se durante o governo de Juscelino Kubitschek como a epítome desse domínio. Construída no Planalto Central, essa conquista do espaço físico de que JK se orgulhava é, em mais de um sentido, uma "cidade criança," e assim é descrita num artigo publicado na revista Realidade em abril de 1967. De um lado, Brasília encarna o projeto nacional brasileiro e, de outro lado, como o menino 
dos anúncios encarregado de preservar o modelo, Brasília tem a missão de recordar aos brasileiros o que é mais importante, ou seja, o progresso e a modernização. Segundo Matías Moreira, Brasília é o símbolo mais perfeito da modernidade; no plano de Lúcio Costa a cidade se assemelha a um avião (13). Moreira cita Carlos Eduardo Comas: "The basic symbolism of the plan is easily understood. It does not require much education to grasp its resemblance to a bird and an airplane, or its transformation of a cross, the sign of foundation, into a bow and arrow, the sign of propulsion" (12). Talvez a cidade tentasse assemelharse ao formato de uma borboleta, mas, na verdade, são as ideias de progresso, avanços tecnológicos e modernização em geral associadas à icônica capital, as que prevalecem no imaginário brasileiro e, aliás, latino-americano.

A crônica "Brasília: cinco dias" escrita por Lispector para a "Children's Corner" em fevereiro de 1963, abre com a afirmação: "Brasília é construída na linha do horizonte. -Brasília é artificial" (90). A cidade criada por Lúcio Costa e Oscar Niemeyer, "dois homens solitários," deixa a escritora com medo e espanto nessa crônica escrita logo após a inauguração da cidade, mas "O medo sempre me guiou para o que eu quero, temo," confessa Clarice (91). Lispector ama e odeia a cidade. Assim, quando escreve uma segunda crônica doze anos depois"Brasília: esplendor," que seria publicada no volume Para não esquecerembora a cidade seja "perfeita e sem erros. E à Clarice [mim] só a [me] salva o erro," a escritora precisa confidenciar: "Adoro Brasília. É contraditório? Mas o que é que não é contraditório?” (Para não esquecer 38, 40). A crônica de Lispector quase não tem uma narrativa; pelo contrário, é uma acumulação de frases descritivas. A mesma Clarice justifica: "Brasília . . . não tem substantivo. É só adjetivo" (Para não esquecer 41). É possível então que a única maneira de a escritora se aproximar da cidade seja, como no caso das personagens nos textos da "Children's Corner," através da intra-ação de que falávamos anteriormente. Esse encontro com o "lugar onde o espaço mais se parece com o tempo" não é um acontecimento, senão uma sensação (Para não esquecer 37). Nesses encontros da escritora e das narradoras com o mundo além do humano, a temporalidade é suspensa, uma vez que, segundo Jack Halberstam, esses modos de relacionamento entre humanos e não humanos são ativados "in each moment and for each context and without a teleology and on behalf of the chaotic potentiality of the random action" (The Queer Art of Failure 80). A simultaneidade da intra-ação se contrapõe à linearidade hetero-reprodutiva 
sinalizada pelo nascimento, o casamento, a reprodução e a morte teorizada por Halberstam, a mesma linearidade das sequências fílmicas do anúncio da loja Serva-Ribeiro.

"Brasília é um futuro que aconteceu no passado" (Para não esquecer 41), mais perto do "queer futurity" do teórico José Esteban Muñoz do que do "reproductive futurism" de Lee Edelman, já que a futuridade de Muñoz aponta para "a potential for a then and there that can be glimpsed in the here and now and disrupt straight time" (32). Conforme diz o teórico queer, atingir ou representar esse potencial é, de certa forma, um fracasso, "a certain mode of virtuosity that helps the spectator exit from the stale and static lifeworld dominated by the alienation, exploitation, and drudgery associated with capitalism" (173). O fracasso queer, então, teria o potencial para rejeitar as ideias normativas de valor que regem a sociedade de consumo das décadas em que foi publicada a revista de Sirotsky, e que moldam em grande parte a revista, ainda com as tensões e contradições antes assinaladas. As colunas de Clarice na revista se desviam das linhas retas heteronormativas descritas por Sara Ahmed, ficam num sentido desorientadas, mas ao mesmo tempo são orientadas para outro mundo além do humano que, por sua vez, gera modos de relacionamento alternativos. Os meninos da "Children's Corner" não reproduzem a linha geracional, essa que segundo Ahmed, tem a ver com a reproduçaõ da heterossexualidade: "a mechanism for the reproduction of culture, or even of the 'attributes' that are assumed to pass along a family line" (161). Em outras palavras, eles rejeitam a lógica de causalidade e legibilidade que impulsiona o projeto modernizador desenvolvimentista ancorado na herança ou na sucessão que garante o avanço do país em direção ao futuro. As crianças da "Children's Corner" com efeito não são "pre-adults figuring the future," senão "anarchic beings who partake in strange and inconsistent temporal logics," como sugere Halberstam ao analisar filmes infantis no seu livro The Queer Art of Failure (120).

Ao passo que o plano de metas de Kubitschek começava a mostrar fissuraso crescimento da inflação e da dívida externa, o atraso do campo e a necessidade duma reforma agrária, a superpopulação das áreas urbanas - e a campanha anticomunista ganhava força, a ênfase na família heterossexual apresentava-se com maior frequência. De um lado, percebia-se a necessidade duma aposta estratégica nos valores familiares para lutar contra as críticas direcionadas ao 
governo. De outro lado, temia-se que o avanço do comunismo-com o precedente de $\mathrm{Cuba}$ - acabaria com a família tradicional. No primeiro número da Senhor é citado Jânio Quadros, sucessor de Kubitschek: "Governo sério é a realização, no âmbito público, dos métodos que, para o lar, desejam o bom chefe de família, a dona de casa, o pai, a mãe" (março 1959, 10). Esse casal heterossexual que inspirava o modelo de governo de Quadros insinua-se desde o primeiro número de Senhor, mas também as vezes aparece na revista uma crítica leve ao modelo de Quadros. Na edição de junho de 1961, por exemplo, hã uma matéria com o título "Para a edificação do Sr. e da Sra.: O Código Civil é masculino," na qual Mariana Peixoto escreve sobre o viés machista do código (43). Com seu gosto pelo desajeitado, pelo errado, pelos atalhos, as criações de Lispector para a revista mobilizam uma dinâmica pós-humanista que reforça e materializa essas tênues contradições da revista que ousou mostrar, ainda que sutilmente, as lacunas do discurso desenvolvimentista.

\section{Obras citadas}

"ABC de utilidades domésticas." Senhor, Suplemento Promocional Loja Serva Ribeiro, jan. 1960, pp. 75-98.

Ahmed, Sara. Queer Phenomenology: Orientations, Objects, Others. Duke UP, 2006.

Anúncio camioneta DKW-Vemag, Senhor, jun. 1960.

Anúncio Fabrica Nacional de Motores, Senhor, nov.1960, p. 10.

Anúncio Nestlé. Senhor, out. 1961, p. 3.

Anúncio Revista Senhor. Senhor, jan.1964, p. 59.

“Alguns senhores e uma senhora." Editorial. Senhor, mar. 1960, p. 7.

Amparo, Flávia Vieira. "Clarice Lispector: From Poetic Corners to Fictional Narrative in Newspapers in the 1940s and 1950s." Clarice Lispector:

Memory and Belonging, The Hebrew $\mathrm{U}$ of Jerusalem, forthcoming.

Arêas, Vilma. Clarice com a ponta dos dedos. Companhia das Letras, 2005.

"Bastidores." Senhor, dez. 1960, 8.

"Bastidores." Senhor, jul. 1961, 8.

"Bastidores." Senhor, jan. 1962, 8. 
Baptista, Íria Catarina Queiróz, and Karen Cristina Kraemer Abreu. "A história das revistas no Brasil: um olhar sobre o segmentado mercado editorial." Biblioteca Online de Ciências de Comunicação. 2010, www.bocc.ubi.pt.

Barad, Karen. "Posthumanist Performativity: Toward an Understanding of How Matter Comes to Mater." Material Feminisms, edited by Stacy Alaimo and Susan Hekman, Indiana UP, 2008, pp. 120-54.

Basso, Eliana Fátima Corti. Revista Senhor: moderninade e cultura na imprensa brasileira. 2005. U Metodista do Estado de São Paulo. PhD Dissertation.

Cerbino, Ana Luiza Fernandes. "Revista Senhor: aspectos comunicacionais de um projeto gráfico." Anais do VI congresso nacional de história da mídia, U Federal Fluminense, 2008.

Edelman, Lee. No Future: Queer Theory and the Death Drive. Duke UP, 2004.

"Encontro com 5 escritores: o que pensam os homens que escrevem." Senhor, jul. 1961, pp. 36-40.

Figueiredo, Anna Cristina Camargo Moraes. "Liberdade é uma calça velha, azul e desbotada": publicidade, cultura de consumo e comportamento político no Brasil (1954-1964). Hucitec, 1998.

Gotlib, Nádia Battella. Uma vida que se conta. U de São Paulo, 2013.

Halberstam, J. Jack. In a Queer Time and Place: Transgender Bodies, Subcultural Lives. New York UP, 2005.

—. The Queer Art of Failure. Duke UP, 2011.

Jaguar. "O sofisticado: quem é, o que quer, para onde vai." Senhor, jan. 1963, pp. 69-71.

Lispector, Clarice. A legião estrangeira. Editora do Autor, 1964.

—. "A repartição dos pães." "Children's Corner," Senhor, jun. 1962, p. 4.

—. "Brasília: cinco dias." "Children's Corner," Senhor, fev. 1963, pp. 90-91.

—. "Brasília: esplendor." Para não esquecer. Ática, 1978, pp. 37-52.

—. "Crítica leve." "Children's Corner," Senhor, jan. 1963, p. 78.

—. "Esboço de um guarda-roupa." Senhor, fev. de 1962, p. 8.

—. "Instantâneo de uma senhora." Senhor, out. 1961, p. 6.

—. "O crime do professor de matemática." Senhor, jun. 1959, p. 76-78.

—. Outros escritos. Edited by Teresa Montero and Lícia Manso, Rocco, 2005.

—. "Submissão ao processo." Senhor, out. 1961, p. 6.

—. "Tentação." Senhor, jan. 1962, p. 70.

—. "Um amor difícil." Senhor, jan. 1962, p. 4. 
Moreira, Matías. "El paisaje de su insomnio: la dualidad ciudad ideal-ciudad real en las crónicas de Clarice Lispector sobre Brasília." Forthcoming.

Muñoz, José Esteban. Cruising Utopia: The Then and There of Queer Futurity. New York UP, 2009.

Nunes, Aparecida Maria. "Sem botar banca, Clarice escreve e aguenta o Brasil." Revista da Anpoll, vol. 1, no. 3, 2012, doi.org/10.18309/anp.v1i33.629.

Pickering, Andrew. The Mangle of Practice. U of Chicago P, 1995.

Vieira, Patricia. "Interspecies Literature: Clarice Lispector's Zoophytographia." Journal of Lusophone Studies, vol. 2, no. 2, 2017, pp. 70-85.

Wolfe, Joel. "From Working Mothers to Housewives: Gender and Brazilian Populism from Getúlio Vargas to Juscelino Kubitschek." Gender and Populism in Latin America: Passionate Politics, edited by Karen Kampwirth, Pennsylvania State UP, 2010, pp. 91-109. 